\title{
The role of $N$-substitution in the intramolecular
}

\author{
cyclizations of aziridines with $\pi$-nucleophiles.
}

\section{Synthesis of 2-azabicyclo[3.2.1]octanes.}

\author{
Aravinda Pulipaka and Stephen C. Bergmeier* \\ Department of Chemistry \& Biochemistry, Clippinger Laboratories, Ohio University, \\ Athens, Ohio 45701, USA
}

bergmeis@ohio.edu

Contents $1-2$

Materials and Methods........................................................................................

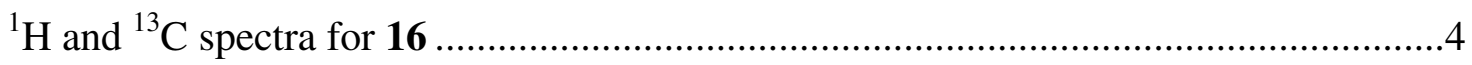

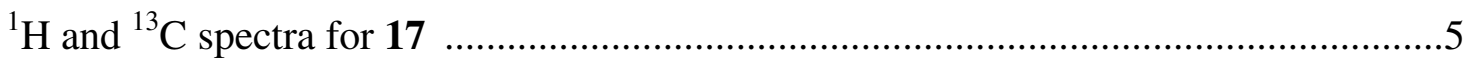

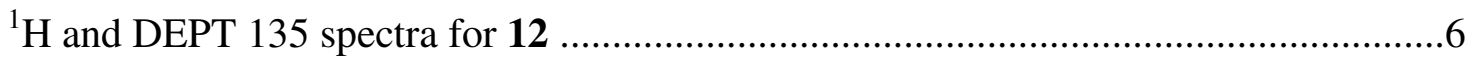

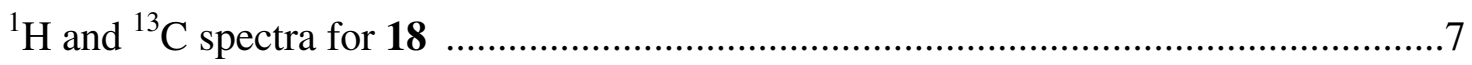

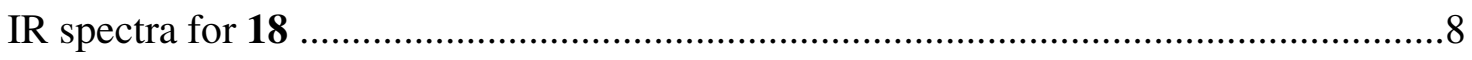

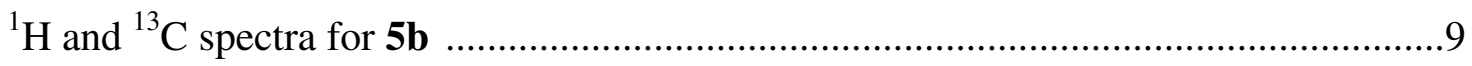

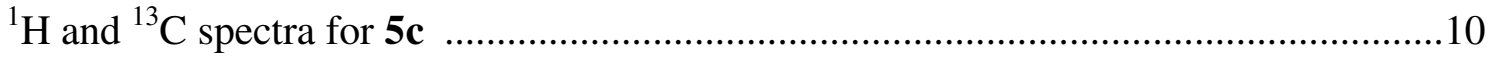


${ }^{1} \mathrm{H}$ and ${ }^{13} \mathrm{C}$ spectra for $\mathbf{5 d}$

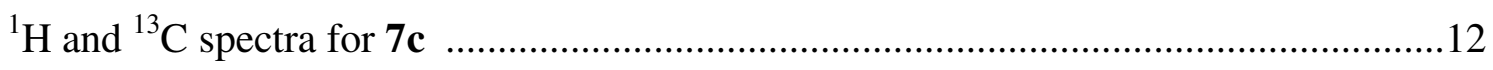

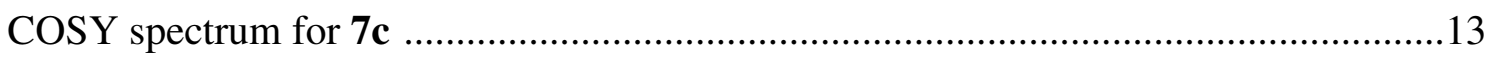

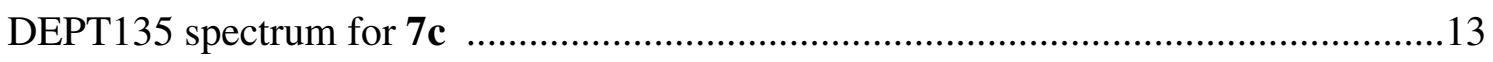

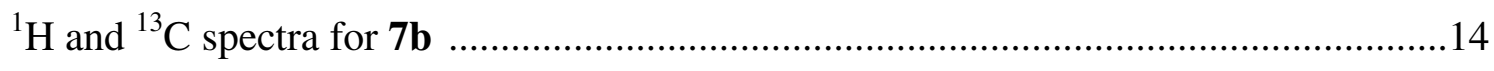

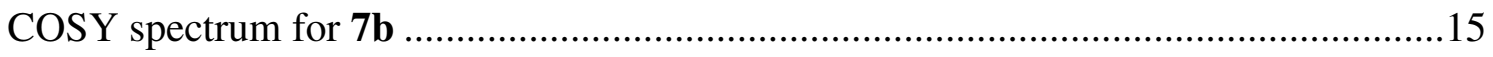

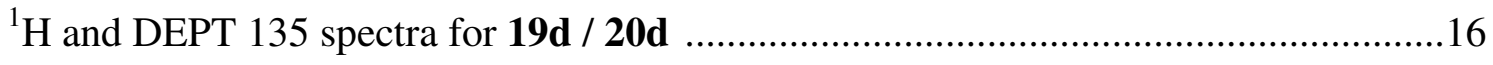

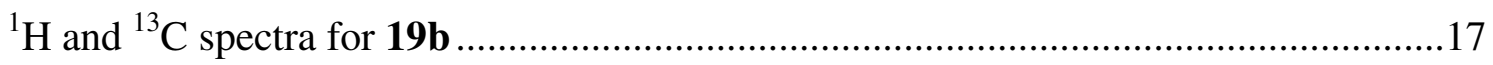

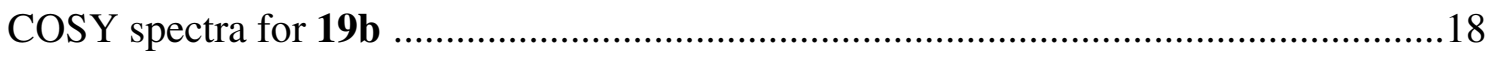

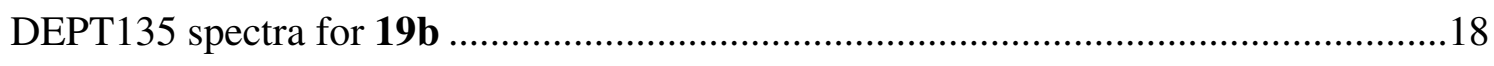




\section{Materials and Methods}

All chemicals were purchased from the usual commercial suppliers and used without further purification unless noted. THF and $\mathrm{CH}_{2} \mathrm{Cl}_{2}$ were dried using a column purification system. IRs were obtained neat. $\mathrm{R}_{f}$ 's were obtained by thin layer chromatography on aluminum backed, silica coated, TLC plates containing a fluorescent $(254 \mathrm{~nm})$ indicator. Spots were identified via UV or staining with ninhydrin/ethanol mixture followed by heating. Compounds were purified by either an automated flash purification system utilizing silica gel or Biotage KP-NH cartridges or by flash chromatography using 3263D $60 \AA$ silica gel according to the method of Still. ${ }^{1}$ NMRs were obtained at $300\left({ }^{1} \mathrm{H}\right)$ or $75 \mathrm{MHz}\left({ }^{13} \mathrm{C}\right)$. Nomenclature for NMR spectra is as follows: $\mathrm{s}=$ singlet, bs = broad singlet, $\mathrm{d}=$ doublet, $\mathrm{dd}=$ doublet of doublets, $\mathrm{t}=$ triplet, $\mathrm{m}=$ multiplet.

\footnotetext{
${ }^{1}$ Still, W. C.; Kahn, M.; Mitra, A. J. Org. Chem. 1978, 43, 2923.
} 

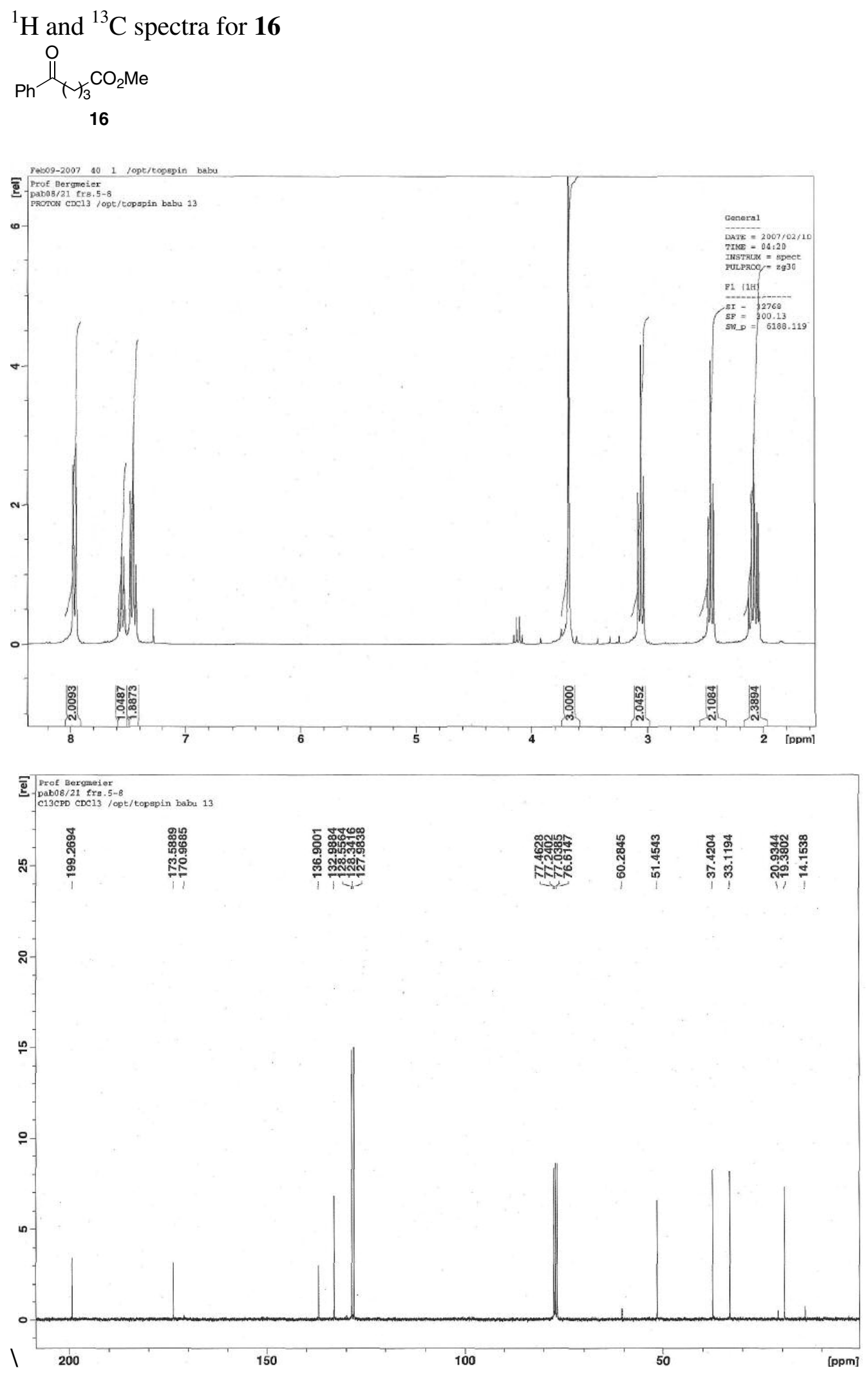
${ }^{1} \mathrm{H}$ and ${ }^{13} \mathrm{C}$ spectra for $\mathbf{1 7}$

$\mathrm{Ph} \overbrace{\mathrm{r}_{3}} \mathrm{CO}_{2} \mathrm{Me}$

17

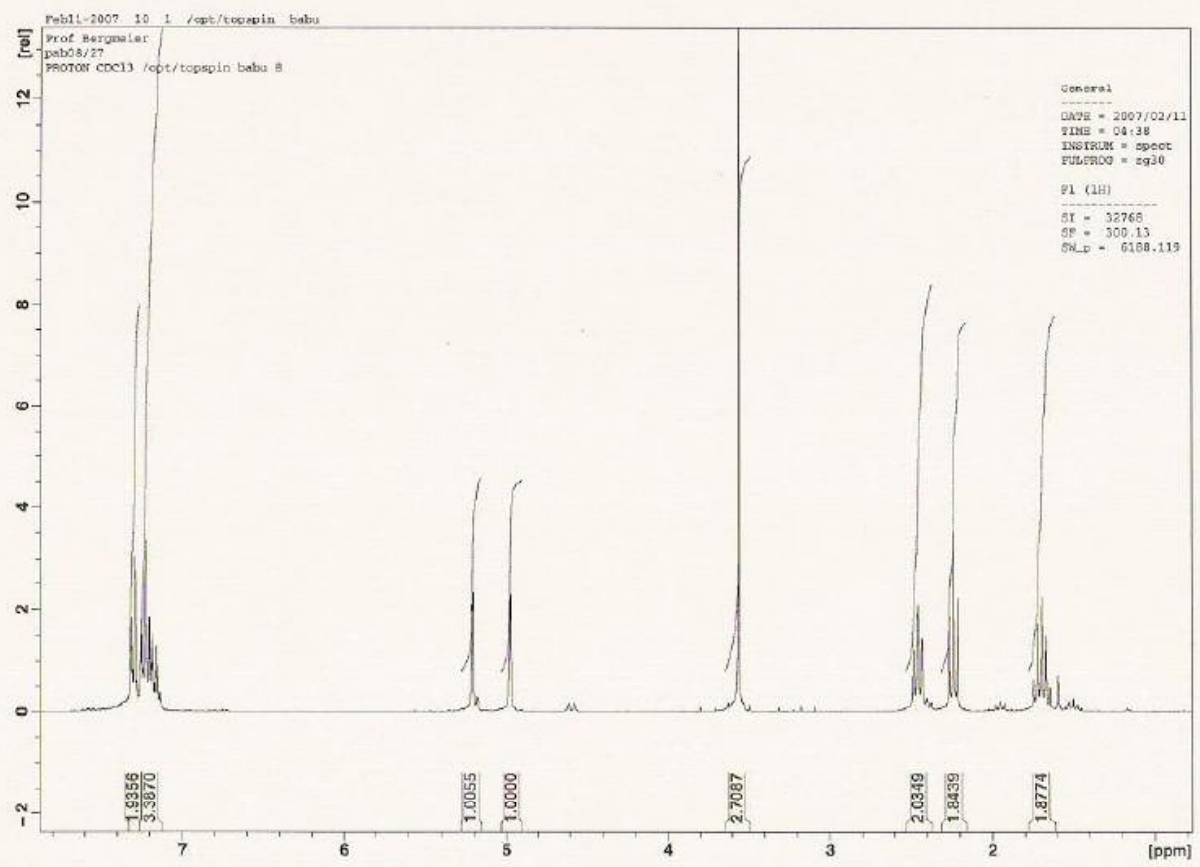

Frabi1-2007 is a fopticopopin babe

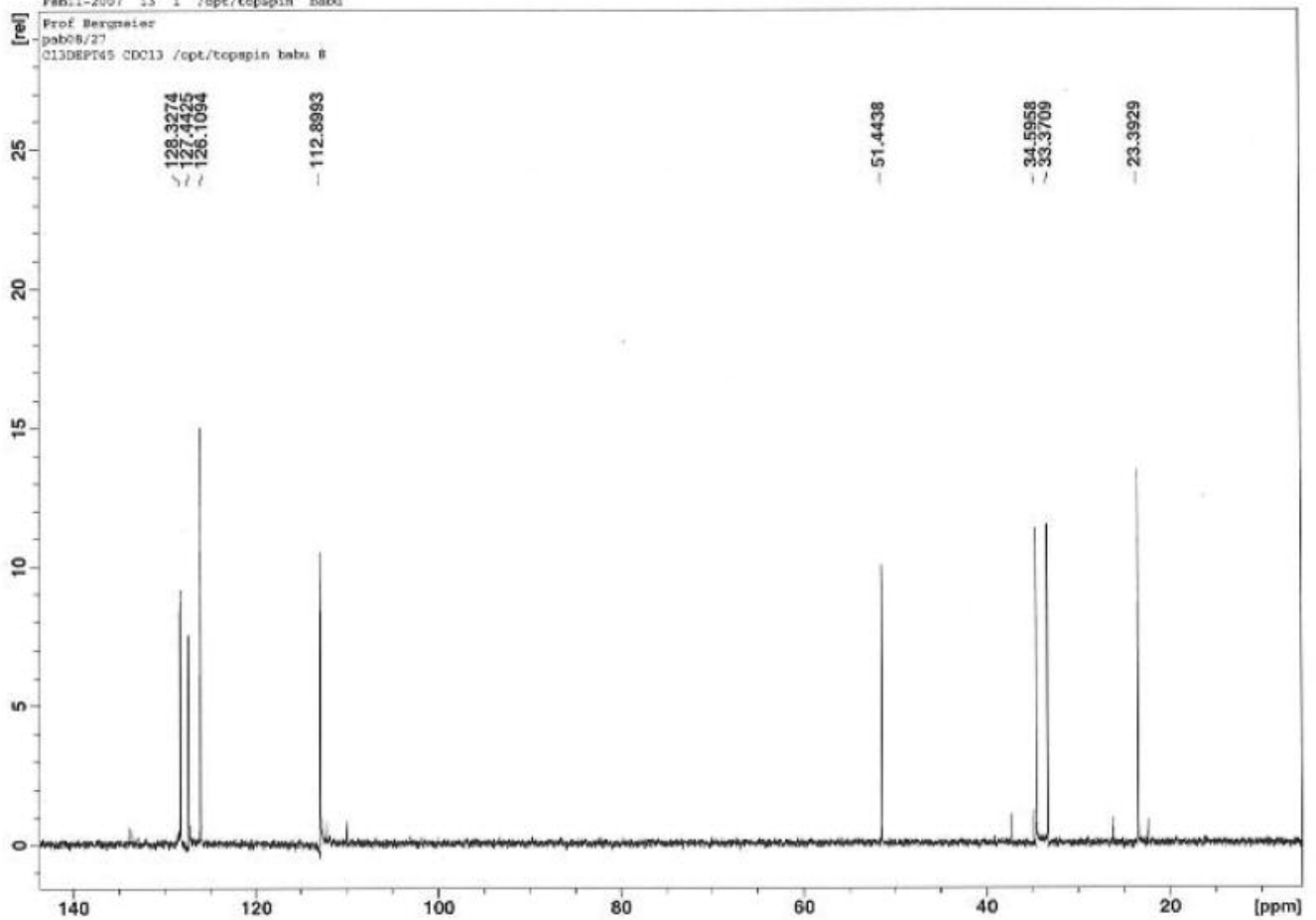


${ }^{1} \mathrm{H}$ and DEPT 135 spectra for $\mathbf{1 2}$

Ph

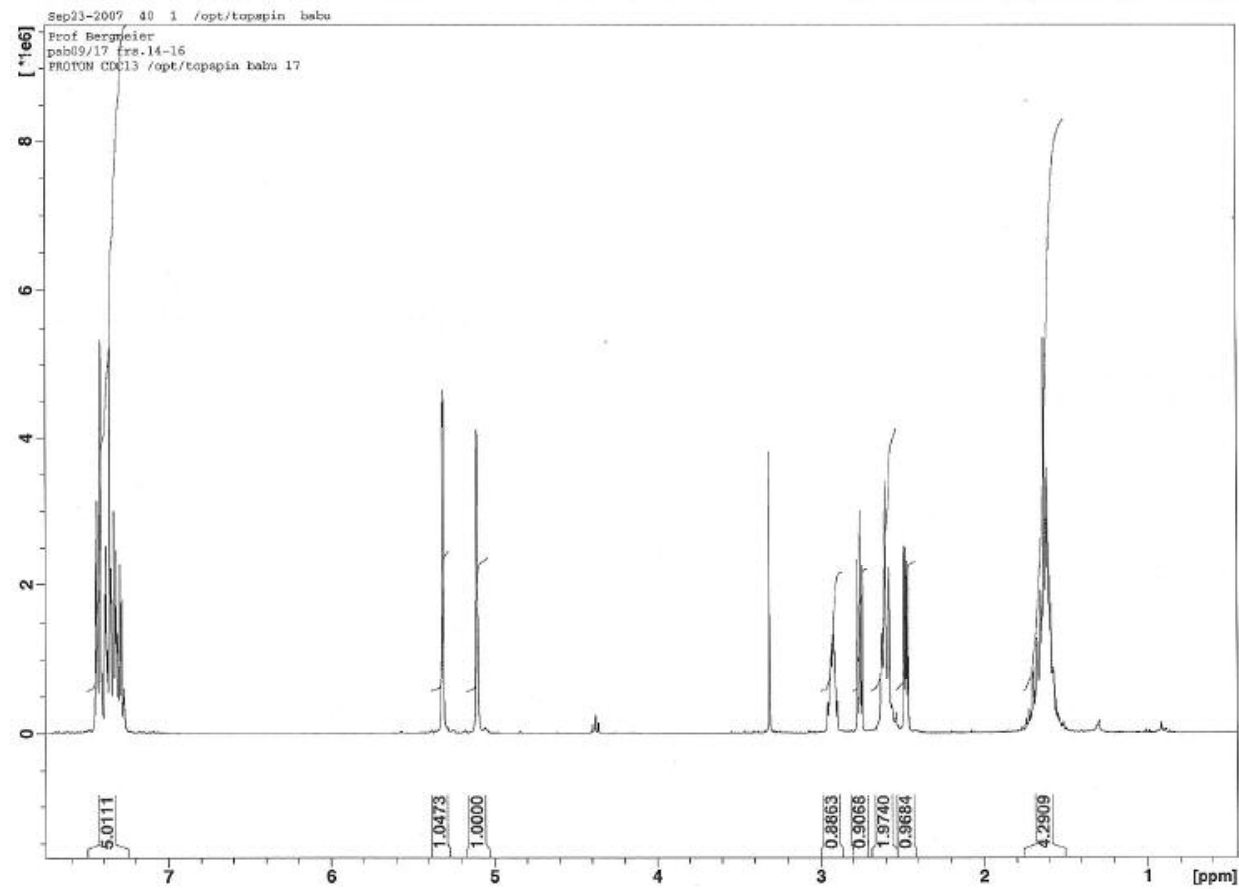

- 3ep23-2007 42 1 iopt/topepia babu

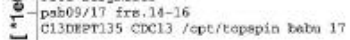

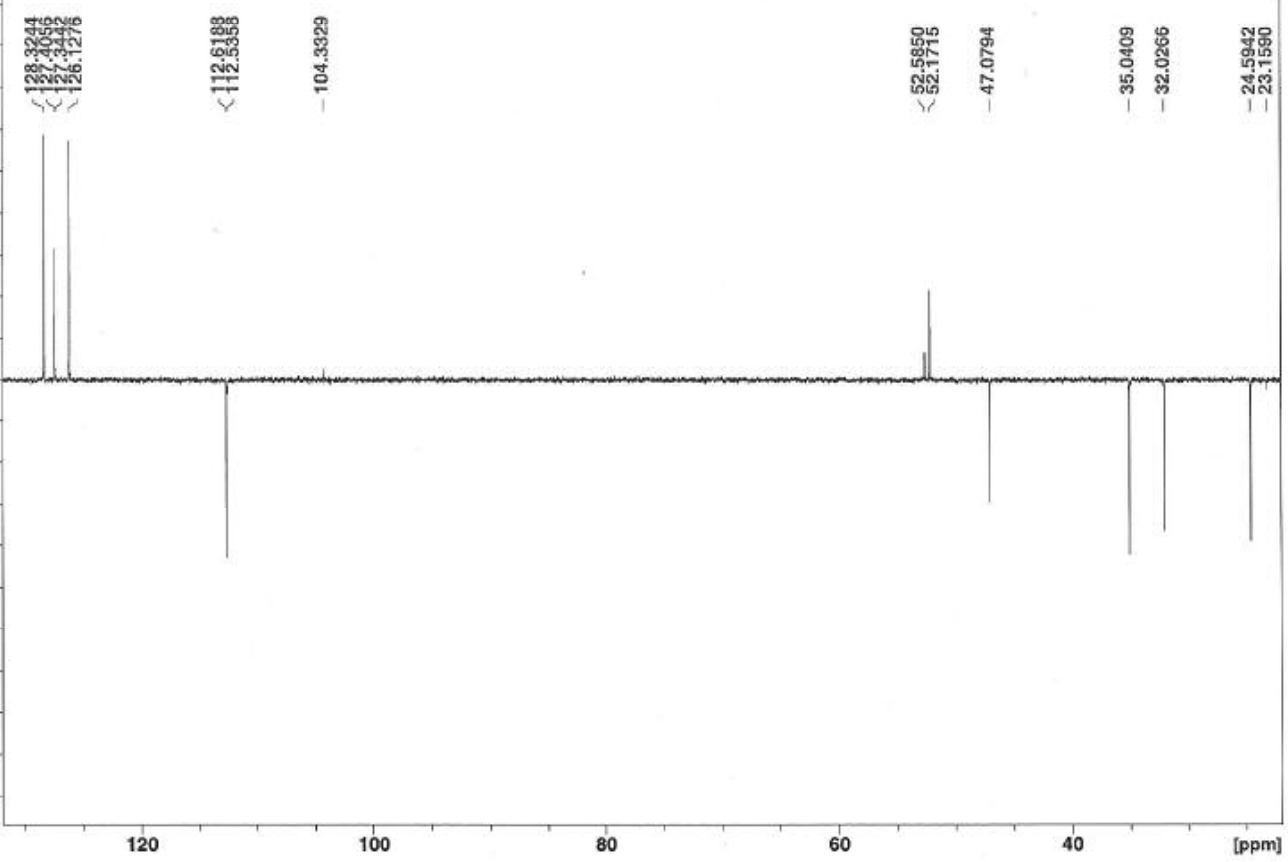


${ }^{1} \mathrm{H}$ and ${ }^{13} \mathrm{C}$ spectra for $\mathbf{1 8}$

$\overbrace{\mathrm{Ch}_{3}}^{\mathrm{OH}} \mathrm{N}_{3}$

18
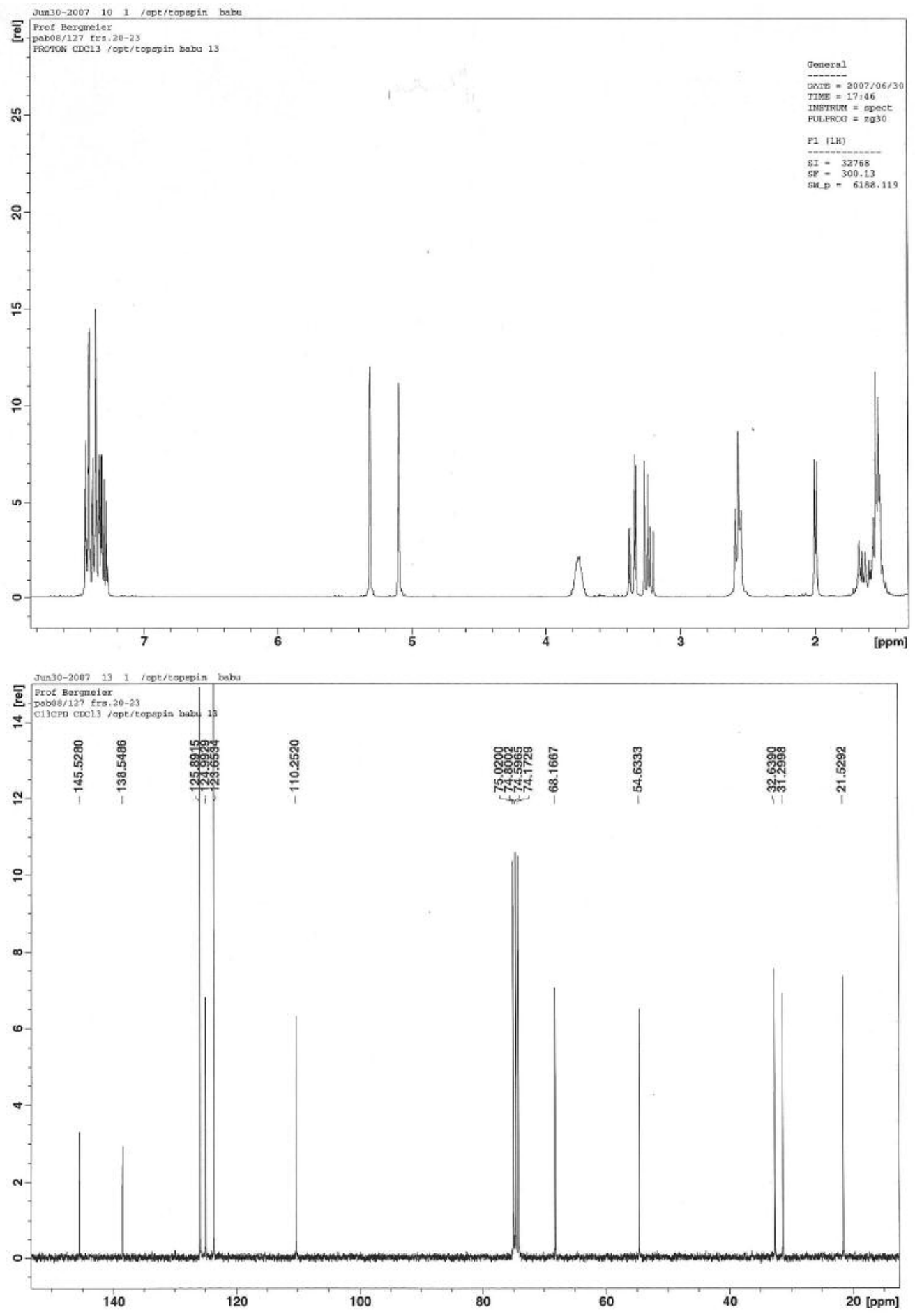


\section{IR spectra for $\mathbf{1 8}$}

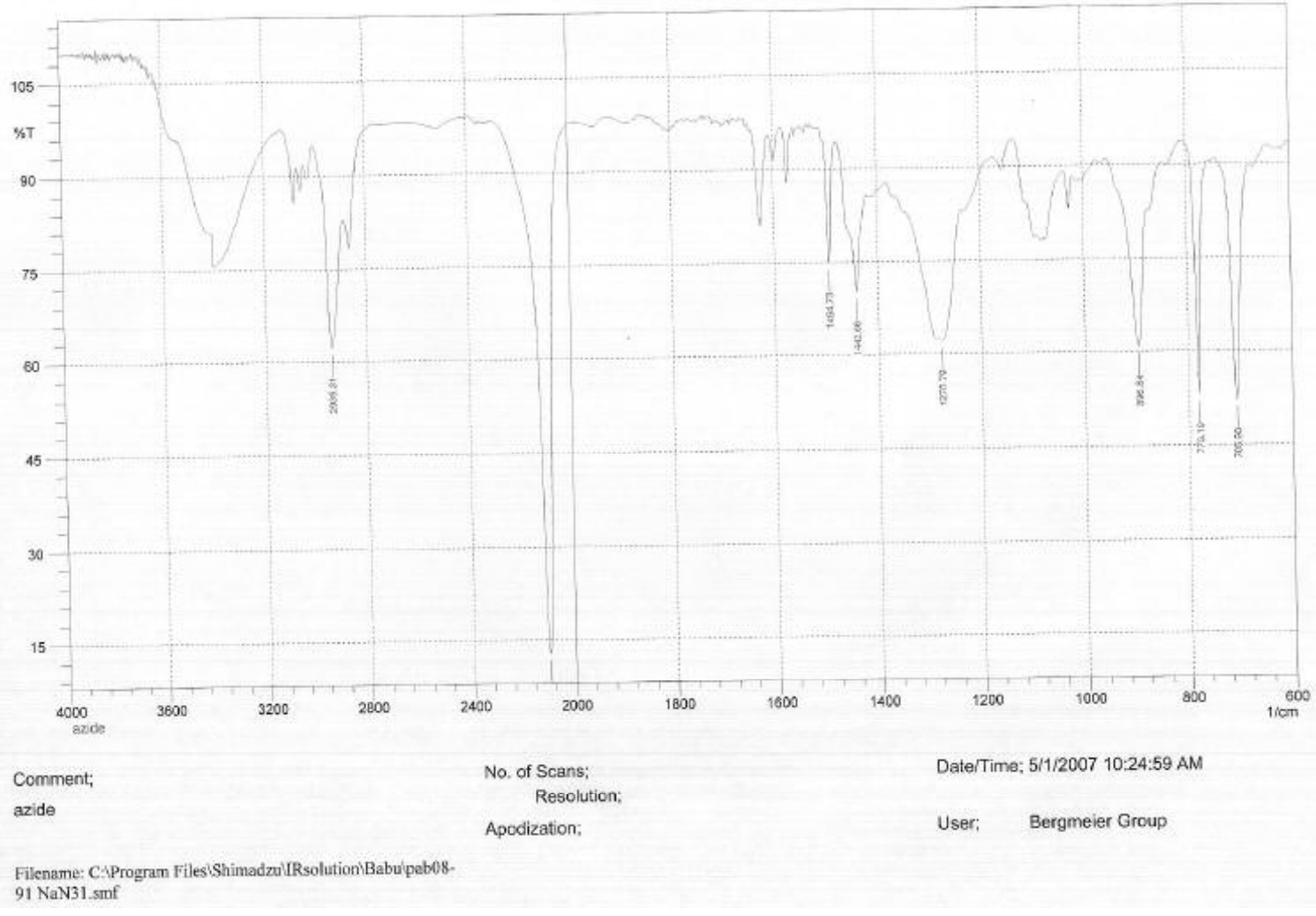


${ }^{1} \mathrm{H}$ and ${ }^{13} \mathrm{C}$ spectra for $\mathbf{5 b}$
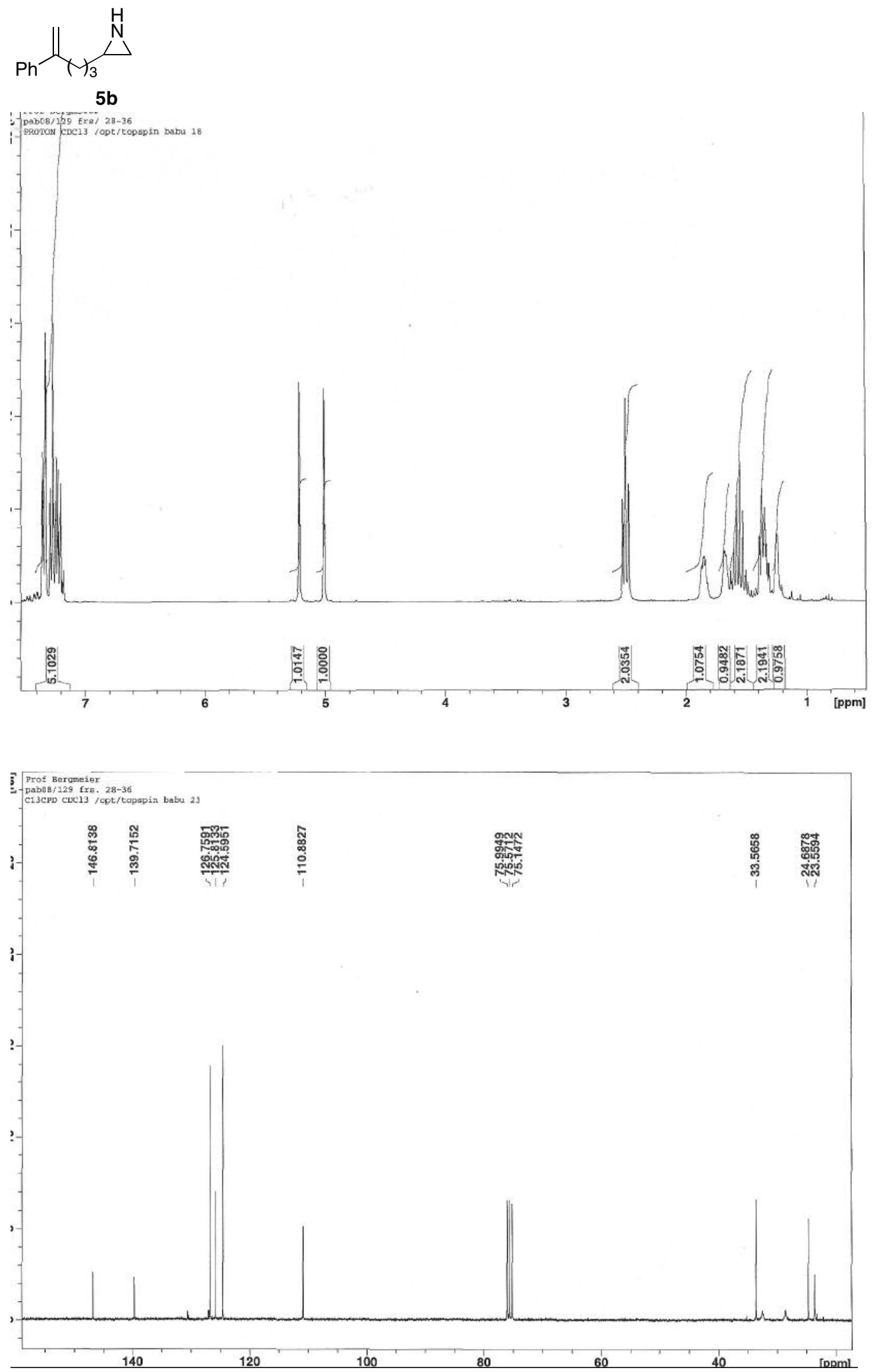
${ }^{1} \mathrm{H}$ and ${ }^{13} \mathrm{C}$ spectra for $\mathbf{5 c}$
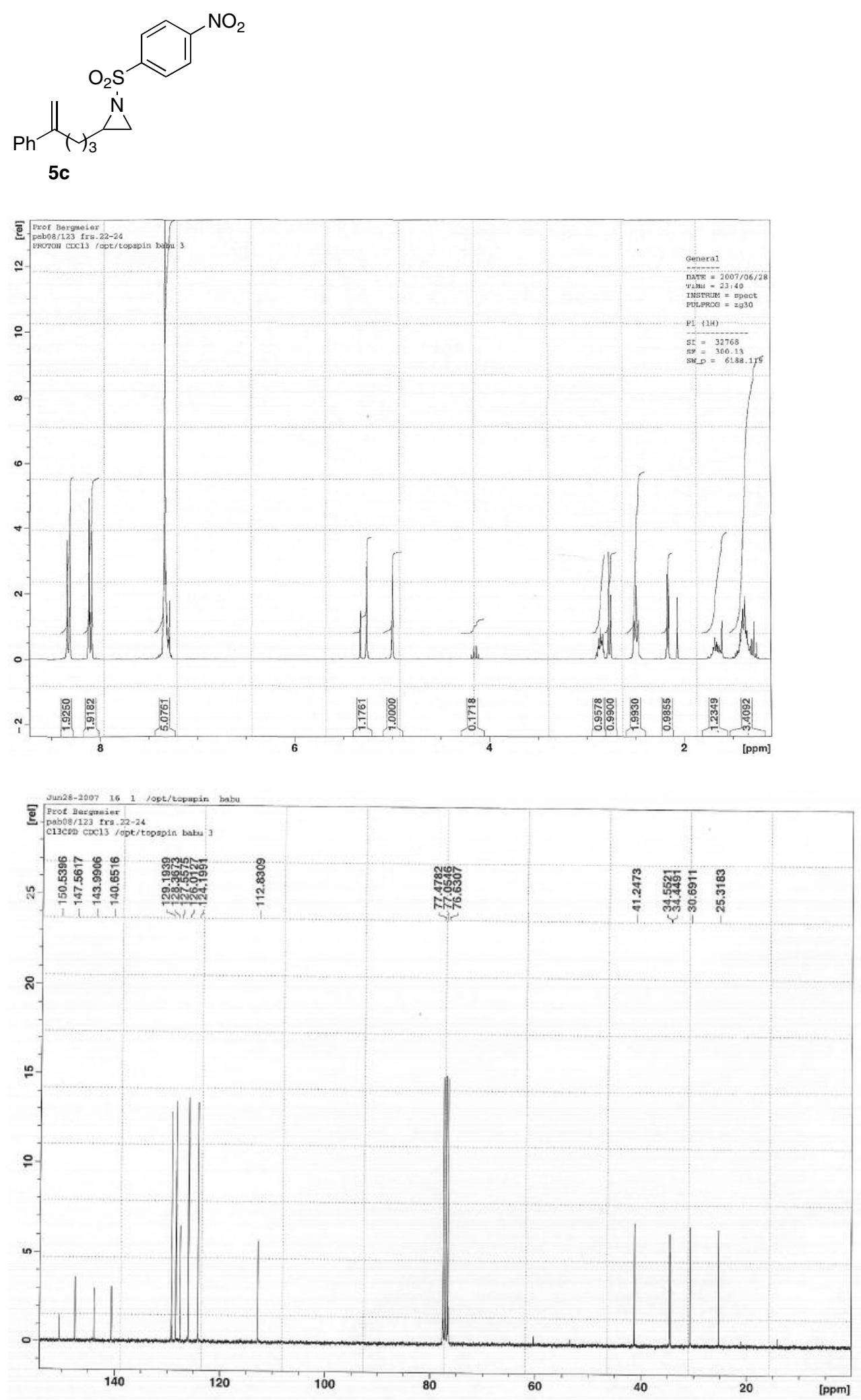

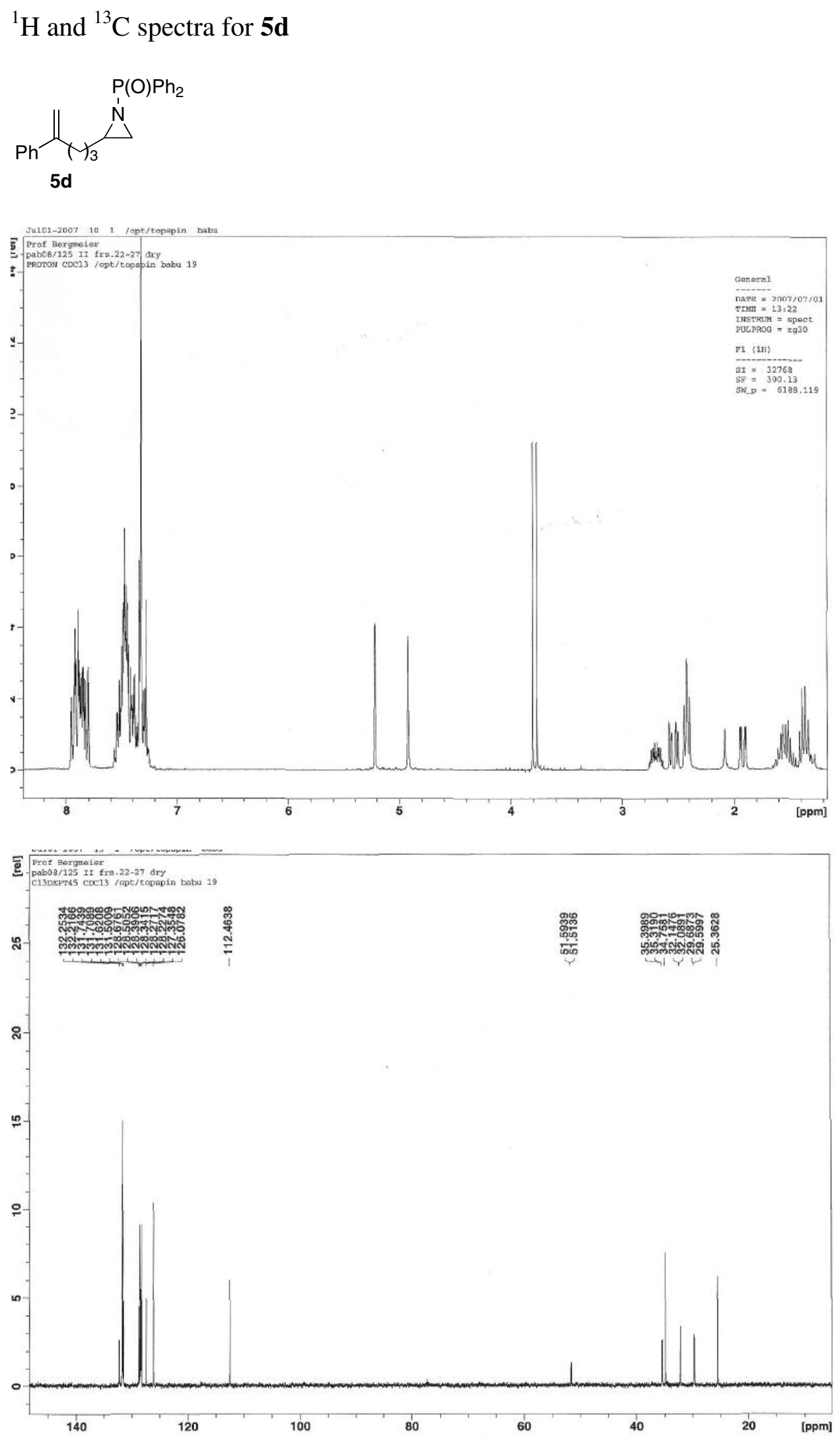

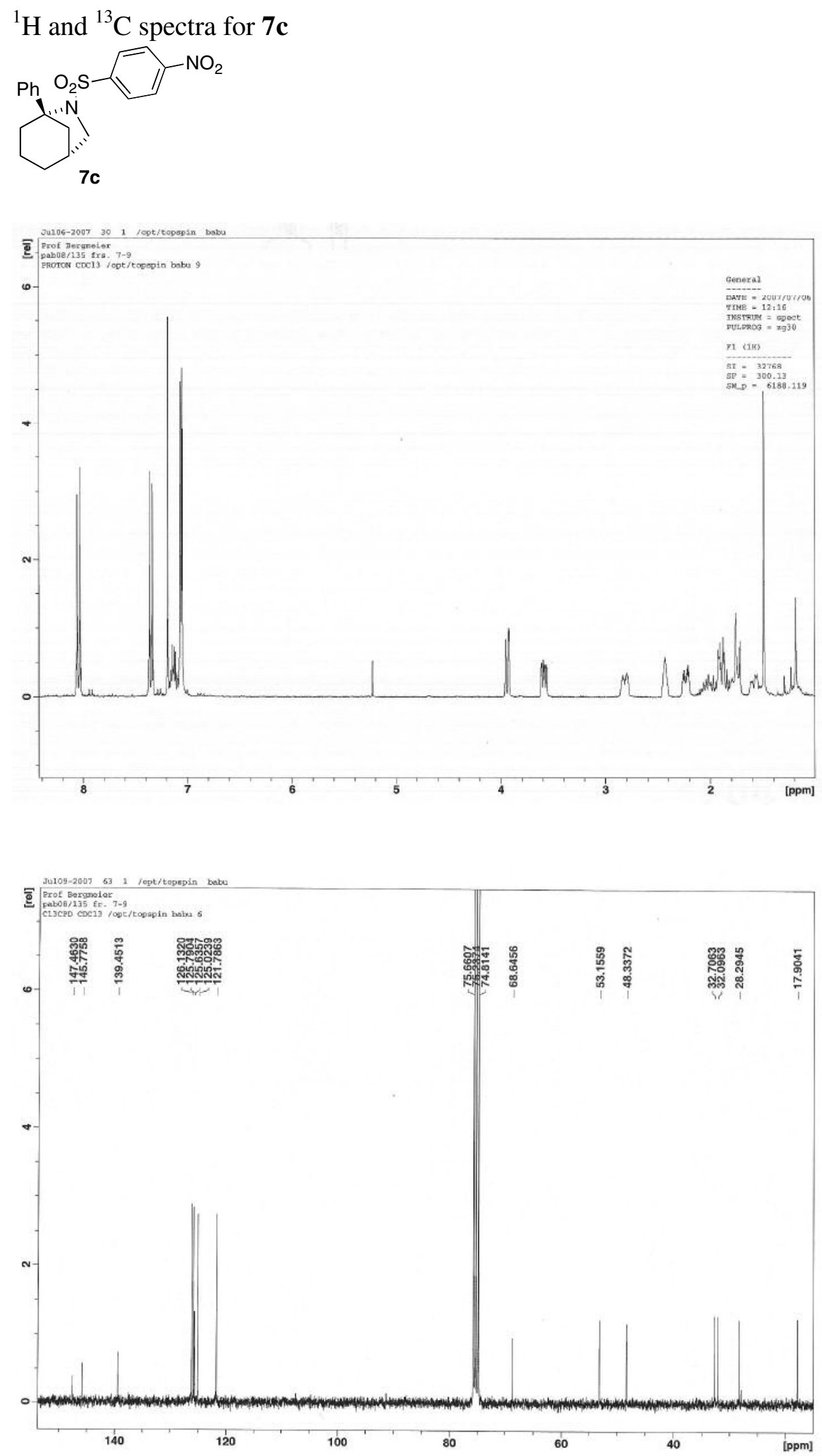
COSY spectrum for $\mathbf{7 c}$

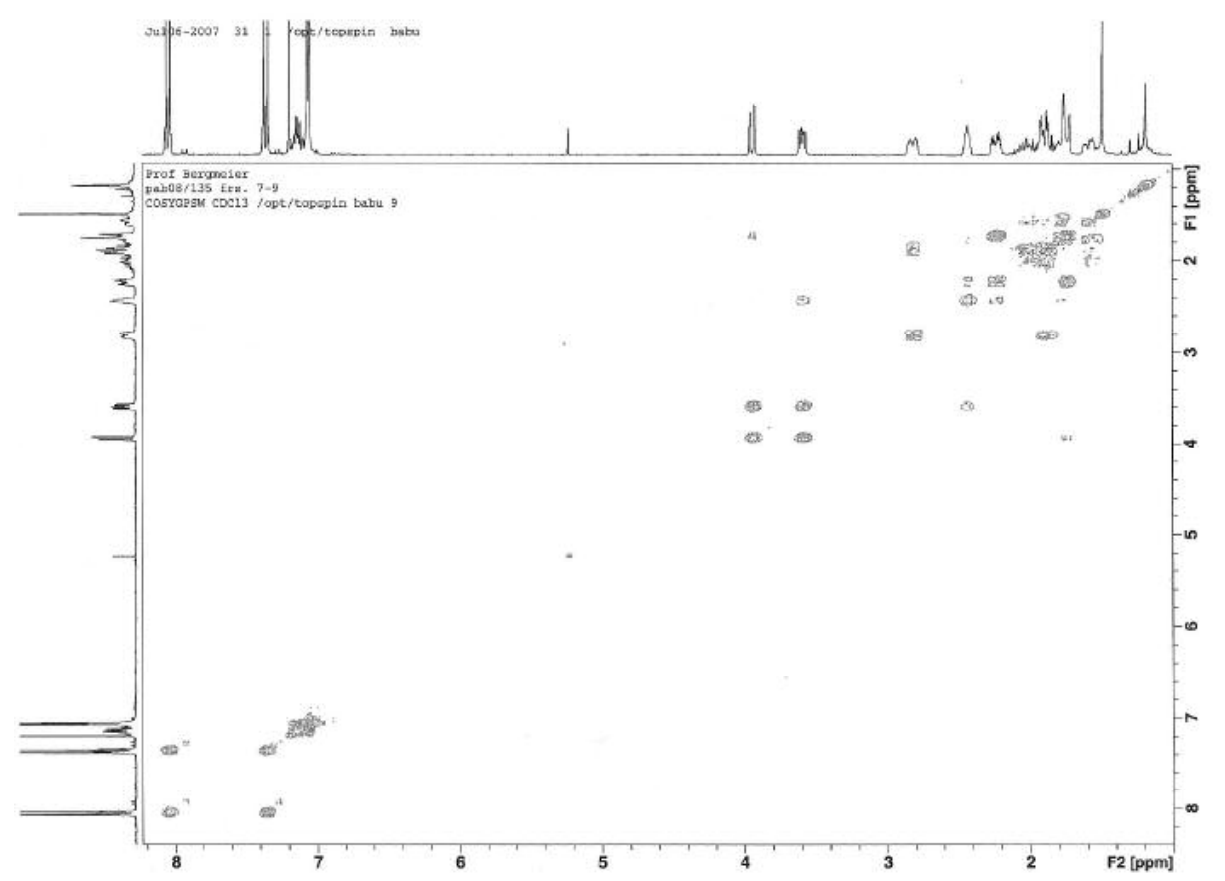

\section{DEPT135 spectrum for 7c}

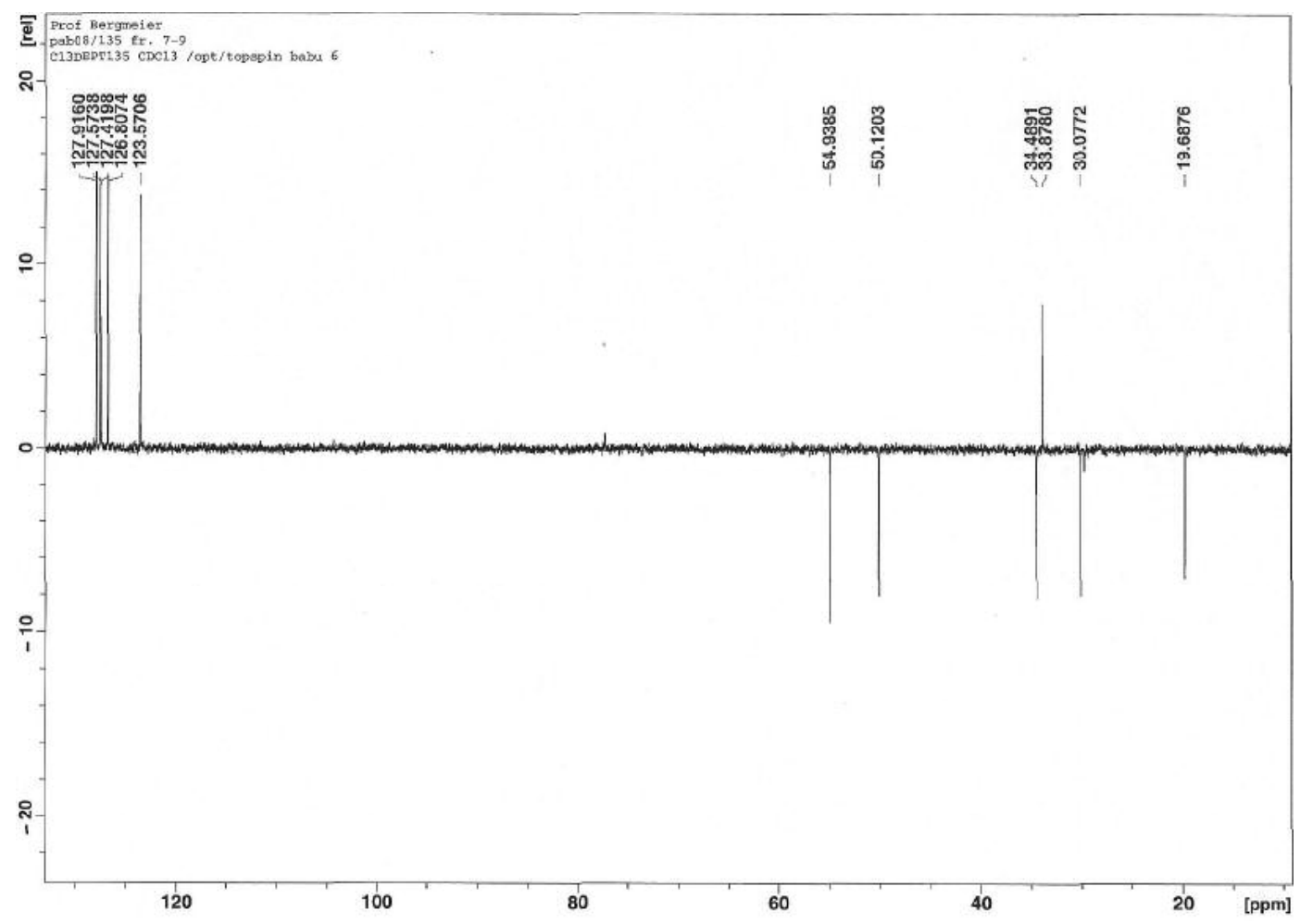



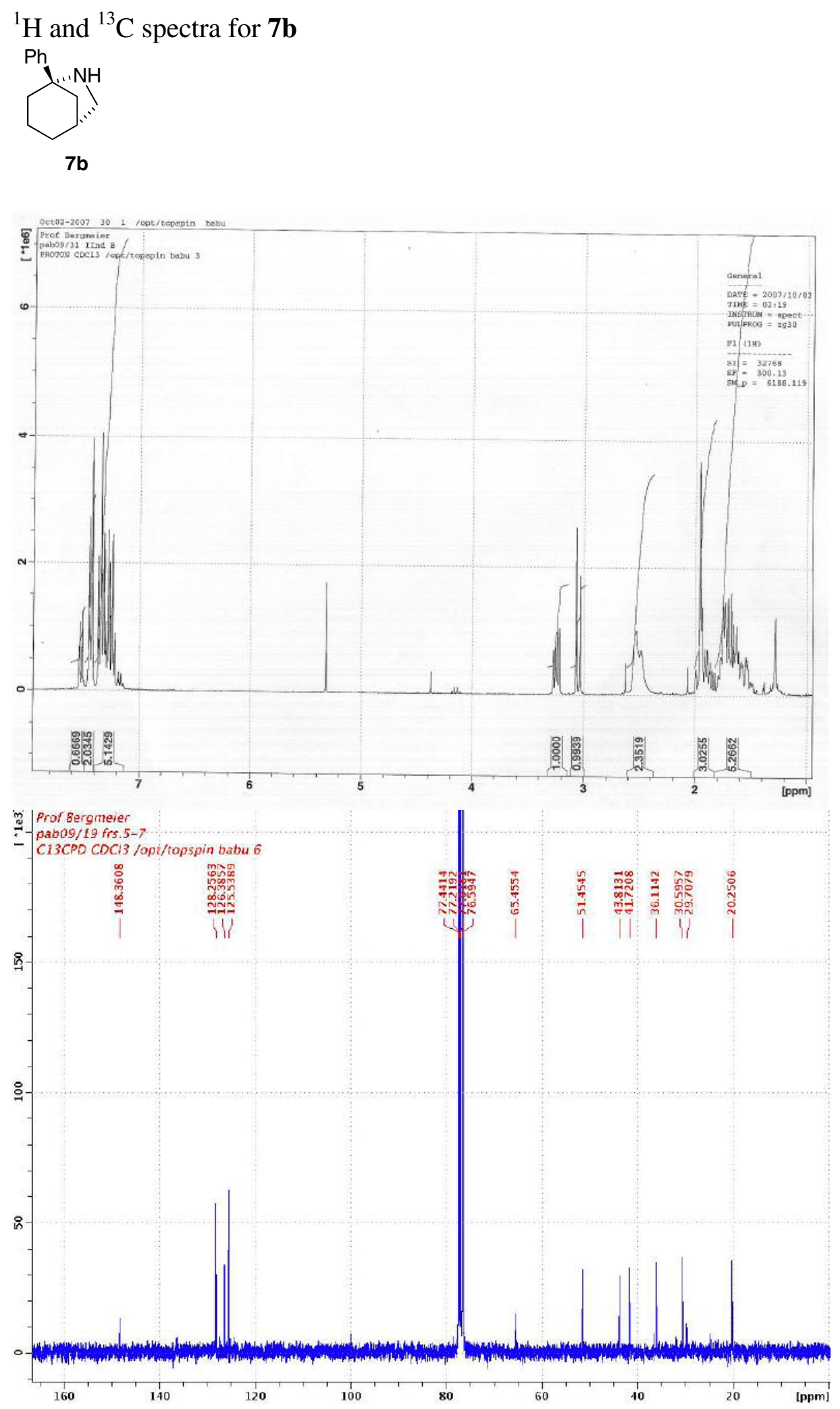


\section{COSY spectrum for $\mathbf{7 b}$}<smiles>c1ccc([C@@]23CCC[C@@H]2CNC3)cc1</smiles>

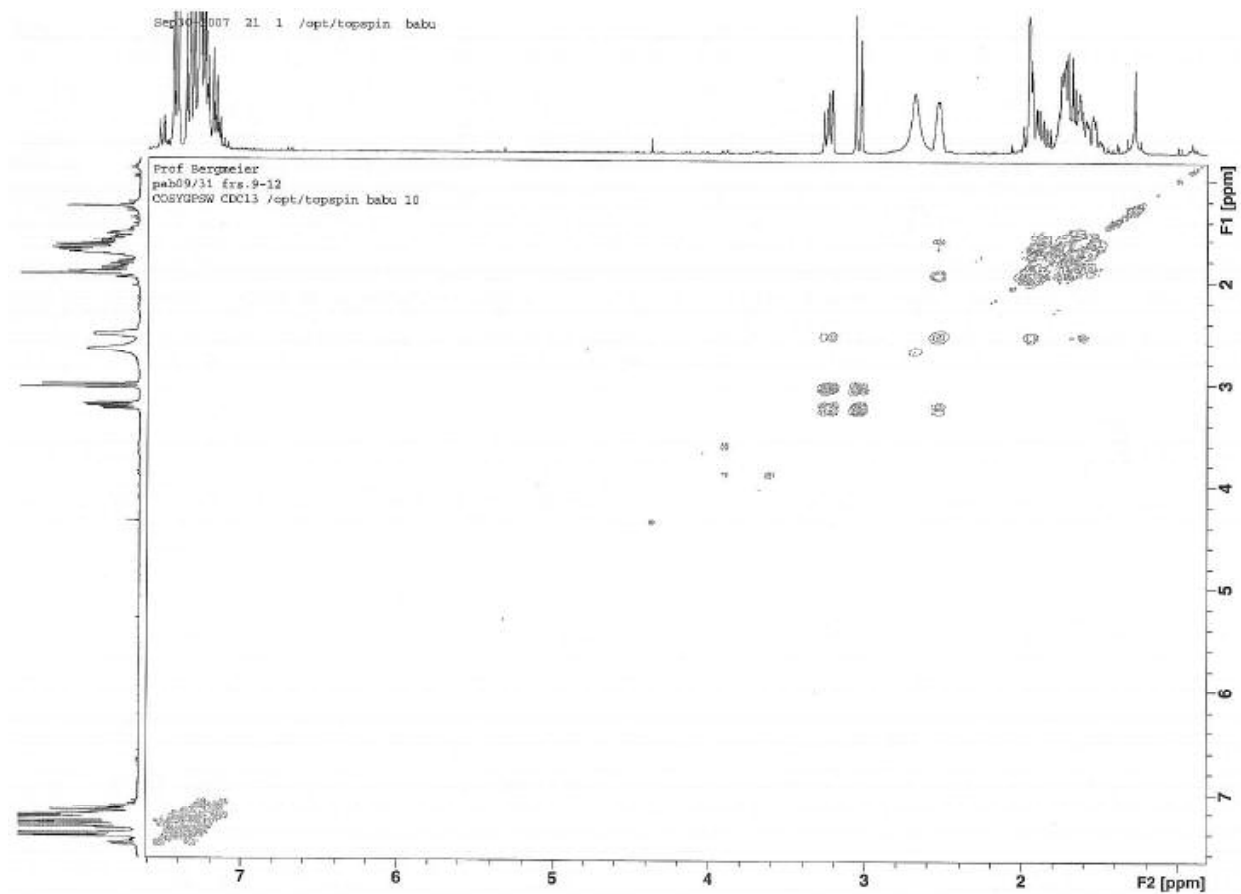


${ }^{1} \mathrm{H}$ and DEPT 135 spectra for $\mathbf{1 9 d} / \mathbf{2 0 d}$<smiles>C(=NCC1C=C(c2ccccc2)CCC1)C1CCC=C(c2ccccc2)C1</smiles>
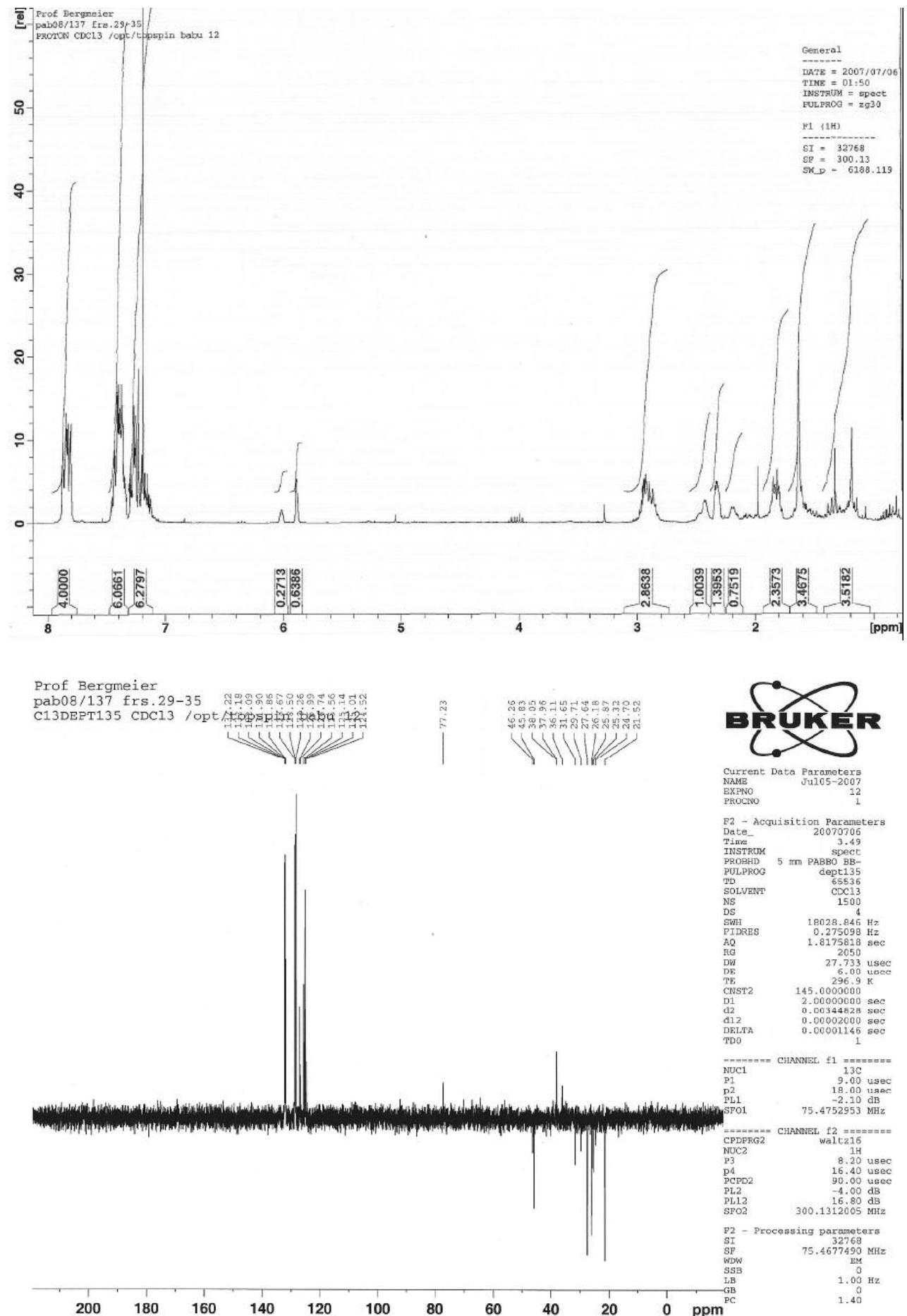
${ }^{1} \mathrm{H}$ and ${ }^{13} \mathrm{C}$ spectra for $\mathbf{1 9 b}$
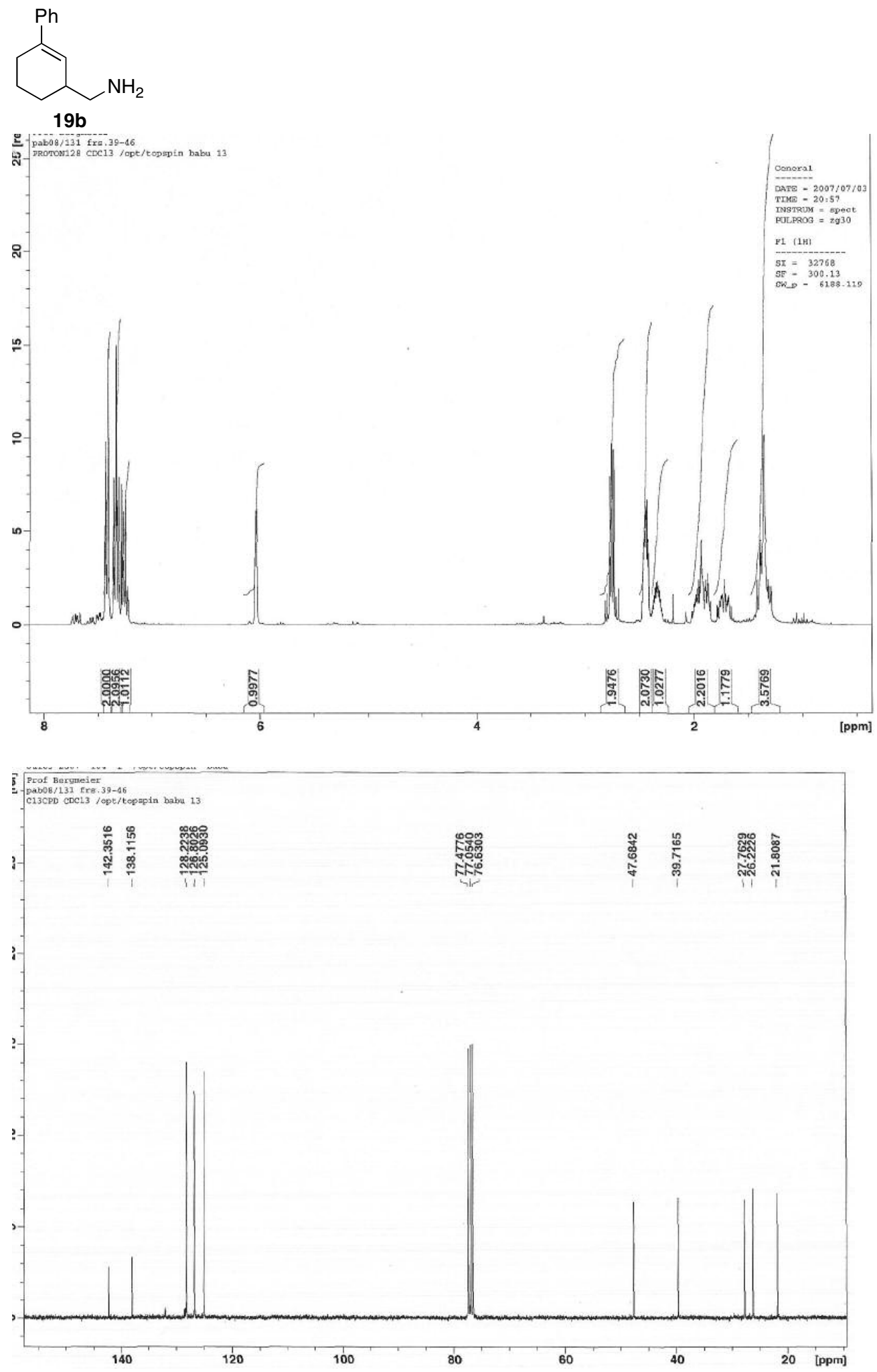


\section{COSY spectra for $\mathbf{1 9 b}$}

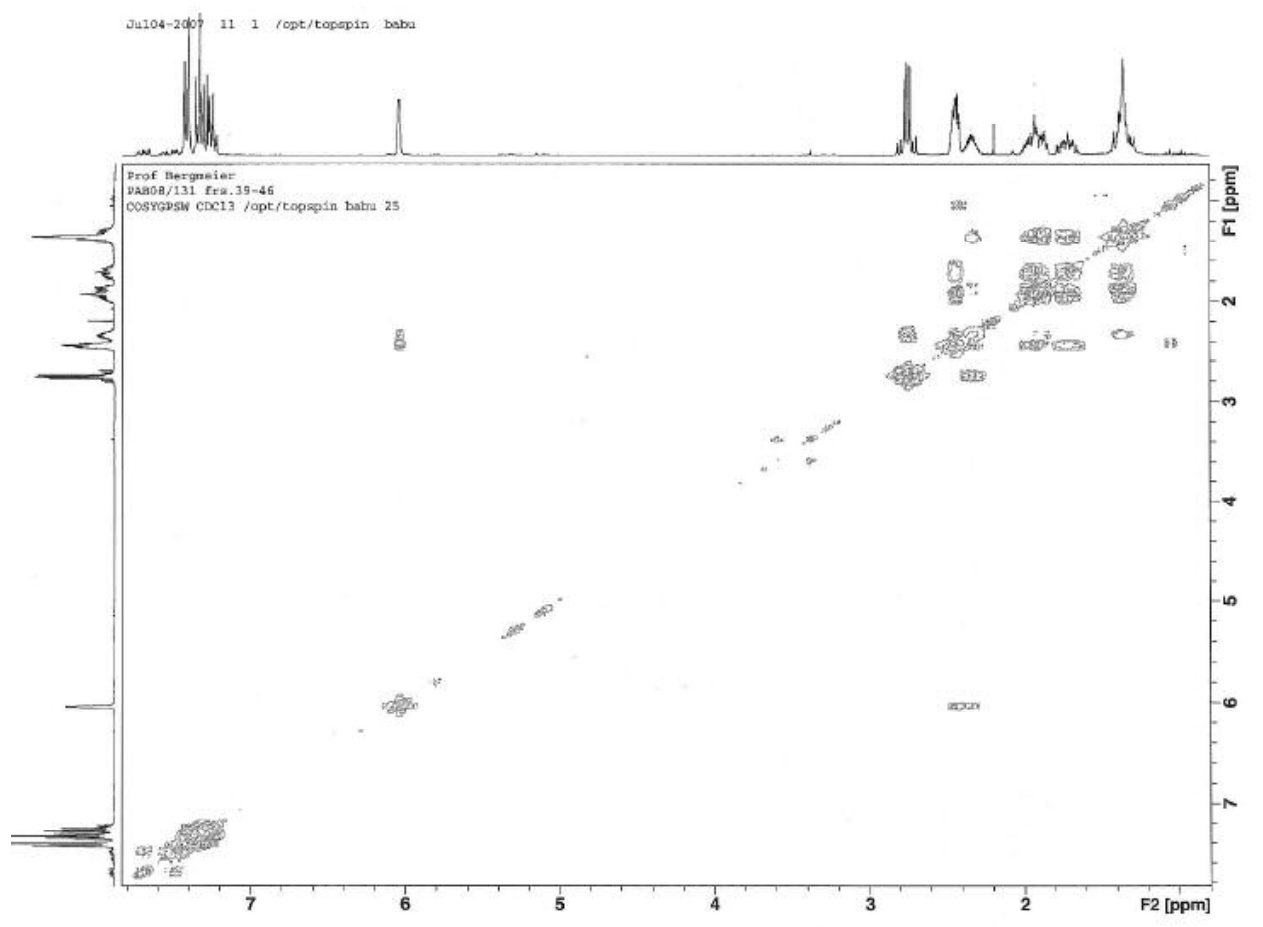

\section{DEPT 135 spectra for $\mathbf{1 9 b}$}

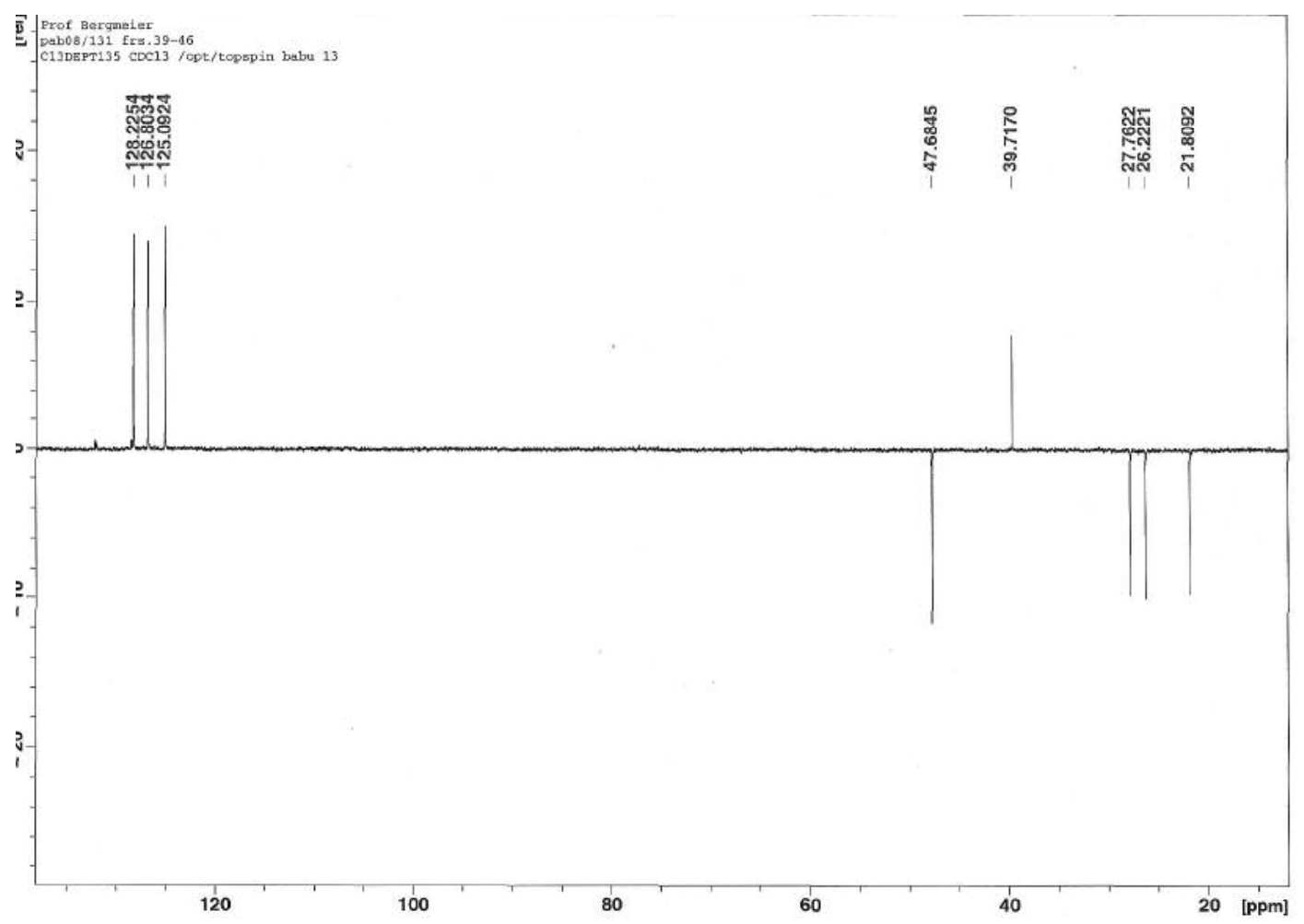

